\title{
Review of Physics Methodology of ATR Safety Analysis
}

W. W. Little

S. W. Heaberlin

September 1991

Prepared for

EG\&G Idaho, Inc.

under a Related Services Agreement

with the U.S. Department of Energy

Contract DE-AC06-76RLO 1830

Pacific Northwest Laboratory

Operated for the U.S. Department of Energy

by Battelle Memorial Institute 


\title{
DISCI AIMER
}

This report was prepared as an account of work sponsored by an agency of the United States Government. Neither the United States Government nor any agency thereof, nor Battelle Memorial Institute, nor any of their employees, makes any warranty, expressed or implied, or assumes any legal liability or responsibility for the accuracy, completeness, or usefulness of any information, apparatus, product, or process disclosed, or represents that its use would not infringe privately owned rights. Reference herein to any specific commercial product, process, or service by trade name, trademark, manufacturer, or otherwise does not necessarily constitute or imply its endorsement, recommendation, or favoring by the United States Government or any agency thereof, or Battelle Memorial Institute. The views and opinions of authors expressed herein do not necessarily state or reflect those of the United States Government or any agency thereof.

\author{
PACIFIC NORTHWEST LABORATORY \\ operated by \\ BATTELLE MEMORIAL INSTITUTE \\ for the \\ UNITED STATES DEPARTMENT OF ENERGY \\ under Contract DE-ACO6-76RLO 1830
}

Printed in the United States of America

Available to DOE and DOE contractors from the

Office of Scientific and Technical Information, P.O. Box 62, Oak Ridge, TN 37831 ; prices available from (615) 576-8401. FTS 626-8401.

Available to the public from the National Technical Information Service,

U.S. Department of Commerce, 5285 Port Royal Rd., Springfield, VA 22161 
PNL --7825

DE92 000436

REVIEW OF PHYSICS METHODOLOGY OF ATR SAFETY ANALYSIS

W. W. Little

S. W. Heaberlin

September 1991

Prepared for EG\&G Idaho, Inc. under a Related Services Agreement with the U.S. Department of Energy Contract DE-AC06-76RLO 1830

Pacific Northwest Laboratory

Richland, Washington 


\section{SUMMARY}

At the request of EG\&G Idaho, the Pacific Northwest Laboratory (PNL) performed a brief review of the physics methods employed in the safety analyses for the Advanced Test Reactor. PNL determined that the general approach used by EG\&G was sound. Comparisons were made between the EG\&G results and a simplified PNL model. These demonstrated good agreement. However, the lack of spacial treatment of the moderator density reactivity coefficient and exclusion of the test loops from the reactivity model were identified as potential problems. In addition to these two concerns, a series of more minor observations were offered to assist EG\&G in their analyses. 


\section{CONTENTS}

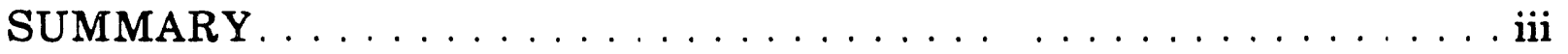

1.0 INTRODUCTION $\ldots \ldots \ldots \ldots \ldots \ldots \ldots \ldots$

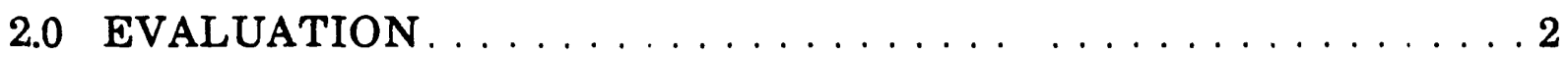

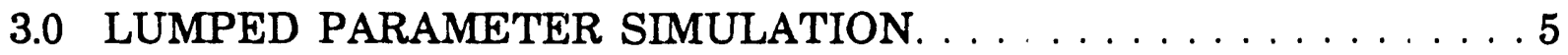

4.0 MISCELLANEOUS OBSERVATIONS $\ldots \ldots \ldots \ldots \ldots$

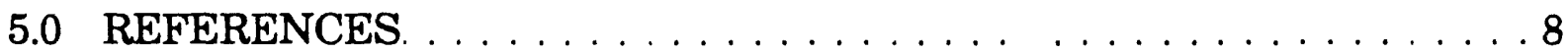

\section{EIGURES}

1. ATR VOID COEFFICIENT $\ldots \ldots \ldots \ldots \ldots \ldots$

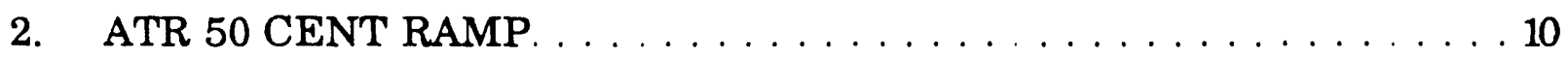

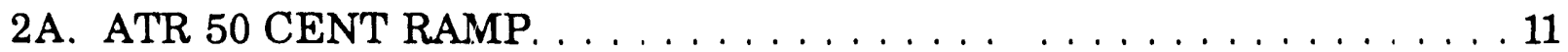

3. ATR 50 CENT RAMP . . . . . . . . . . . . . . . . . 12

3A. ATR 50 CENT RAMP . . . . . . . . . . . . . . . 13

4. ATR 50 CENT RAMP . . . . . . . . . . . . . . . . . . . . 14

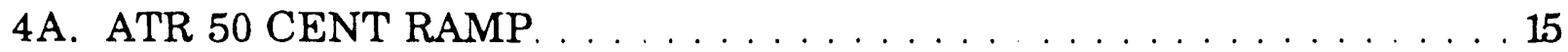

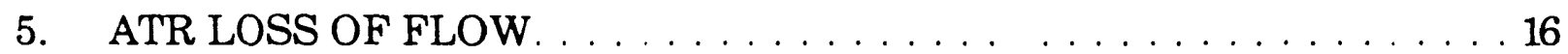

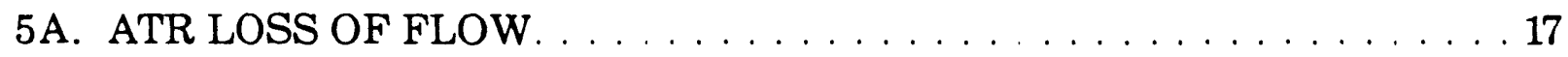

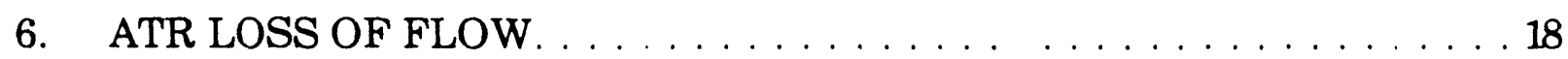

6A. ATR LOSS OF FLOW. . . . . . . . . . . . . . . . . . . . . 19

7. ATR LOSS OF FLOW. . . . . . . . . . . . . . . . . . . . 20

7A. ATR LOSS OF FLOW. . . . . . . . . . . . . . . . . . . . . 21 


\subsection{INTRODUCTION}

During the Summer of 1991, Steve Wagoner of EG\&G Idaho requested that PNL (through Scott Heaberlin) perform a brief review of the physics methodology used by EG\&G Idaho for ATR (Advanced Test Reactor) safety analysis. The basis for the review, or reference material, is contained in two EG\&G Internal Technical Reports (Polkinghorne 1991 and Judd 1991). Specific accidents analyzed in these references include a 50 cent reactivity insertion transient and a loss of flow transient.

After studying the reference material, Scott Heaberlin and Winston Little visited EGG\&G Idaho on 9/10/91 to present preliminary results and to rlarify several questions. This report summarizes PNL's review of the methodology used by EG\&G Idaho for ATR safety analysis. 


\subsection{EVALUATION}

The general approach--that of using a multi-dimensional neutronics code to compute spatial dependent reactivity coefficients, a nodal heat transfer model to compute dynamic temperature distributions, and a lumped parameter neutron kinetics model--has been widely used in the industry for many years. The reason that a full-blown space-time model is not used is that a full-blown model would be prohibitive in complexity--requiring massive computer resources.

The simpler approach used by EG\&G, of separating the space and time neutronics dependence, is generally satisfactory if care is taken in preparing input. And the simpler approach has the added virtue of relative ease of interpretation of input and output parameters.

It is also recognized that the ATR is very difficult to model neutronically. That is, due to the complex geometric arrangement of the ATR core, even statics calculations are challenging. Thus, a time dependent model, that would also accurately reflect the ATR geometric detail, would be essentially beyond current capability.

Although the general conceptual approach appears sound, two specific problems were detected. The first problem concerns formulation for the coolant reactivity coefficient. The coolant reactivity feedback is computed by the expression:

$$
\mathrm{dk}=\mathrm{W}(\mathrm{i}) * \mathrm{R}(\mathrm{rho})
$$

\begin{tabular}{|c|c|c|}
\hline \multirow[t]{3}{*}{ where: } & $\mathrm{dk}$ & $=$ reactivity \\
\hline & $W(i)$ & $=$ coefficient for space node $\mathrm{i}$ \\
\hline & $\begin{array}{l}\mathrm{R}(\text { rho }) \\
\text { rho }\end{array}$ & $\begin{array}{l}=\text { table of reactivity versus rho } \\
=\text { coolant density. }\end{array}$ \\
\hline
\end{tabular}


It is often the case that reactivity is a non-linear function of coolant density--for example, see data from Table 2, page 10, Polkinghorne (1991), which is plotted in attached Fig. 1. Thus, tabulating reactivity as a function of density is reasonable. However, the dependence can change markedly as a function of spatial position. This is because hydrogen worth is composed of three components (moderation, leakage, and capture), and the relative importance of each of these components can change with location. The positive void worth in a test loop, which is the basis for the 50 cent insertion accident discussed in Polkinghorne (1991), is but one example of the variation of coolant worth with spatial position.

There are three potential fixes to this problem. The first, and best, is simply to make $R$ (rho) a function of spatial position, and not just a multiplier of a spatially dependent weighting factor. This requires much more input data, but may be feasible. It is noted that it may not be necessary to input $R$ (rho) for each node point, but at least enough $\mathrm{R}$ (rho)s to span the range of coefficients exhibited by the reactor.

The second approach is to forgo the non-linearity of the feedback, and simply use a linear feedback coefficient at each spatial position. The current formalism could be used-- $R$ would be a constant and W(i) the linear (perturbation) feedback coefficient for position $i$. The approach would probably be satisfactory for the accidents described in Polkinghorne (1991), which do not involve large changes in coolant density.

A third approach, applicable to situations involving the possibility of extensive core voiding, would be to first compute a core average coolant density, and then base the feedback on the core average density (e.g., using data such as shown in Fig. 1). This, however, would not adequately model localized effects, such as the voiding of one coolant channel. 
In any event, it is recommended that the coolant reactivity coefficient, $\mathrm{R}(\mathrm{rho})$, be examined at several locations in the core to determine the significance of the spatial variations.

The second specific problem concerns the treatment of the test loops during a transient. Actually, the problem is essentially the lack of treatment. As shown in Eq.(1), the reactivity feedback is computed by summing over the spatial nodes. Currently, this sum does not include the test loops. These loops could potentially add positive reactivity during a transient due to their positive void coefficient. Although we do not know the magnitude of these feedbacks, the model is nonconservative in the sense that these potentially positive feedback terms are omitted. 


\subsection{LUMPED PARAMETER SIMULATION}

When asked to evaluate the validity of a complex mathematical model--such as the RELAP simulation of the ATR--one not only looks at the mathematical formulation, but also compares results with "back of the envelope" estimates. To this end, a simple lumped parameter kinetics model, involving 3 spatial nodes (fuel, clad, and coolant) and six delayed neutron groups, was used to simulate the two accidents described in Polkinghorne (1991).

The first accident was a 50 cent reactivity insertion in 0.5 seconds. Figures $2-4$ gives the dynamic response in terms of reactivity, power, and temperature. For each figure, two graphs are given. The first portrays the inital details of the transient, and the second is formatted to facilitate comparison with the graphics in Polkinghorne (1991). The results roughly confirm, in timing and magnitude, the RELAP values given in Polkinghorne (1991). The only notable deviation is that the RELAP values show a "downturn" after the initial peak. The "downturn" is caused by variation in inlet temperature, which the simple lumped parameter model did not include.

The second accident is a reduction of flow from $100 \%$ to $11 \%$ in 17 seconds. The results from the lumped parameter model are given in Figures 5-7. Again, the results are generally compatible with the values from RELAP given in Polkinghorne (1991).

An earlier comparison with RELAP exhibited a more gradual drop in reactivity and power. However, when a more representative flow rate, which accounted for the flow to power ratio in the high power lobe, was used in the lumped parameter model, the agreement improved markedly. 


\subsection{MISCELLANEOUS OBSERVATIONS}

In addition to the direct comparisons, a number of more general observations were developed. These are listed below.

- Effect of burnup on the coolant void coefficient. EG\&G personnel reported that earlier analysis indicates that burnup does not have a detrimental effect on the coolant coefficient. It is suggested that this work might be reviewed, or repeated, to insure confidence. It would be appropriate to include some discussion of this in future documents.

- Energy groups used to compute the moderator coefficient. It is noted that the spectrum component of the moderator coefficient is often sensitive to the details of the energy spectrum, and that a many-group model is often necessary to compute accurate coefficients. The methods employed in this analysis for neutron moderation may be weak in this regard.

- Fuel temperature coefficient. The fuel temperature coefficient is reported to be almost negligible compared to the coolant coefficient. Has this been verified by experiment (from either the reactor or the critical)? Since this is the most time responsive coefficient its treatment is important, especially in the more severe reactivity transients.

- Flux tilts. It appears that the possibility of flux tilts due to xenon oscillations or other features have not been thoroughly investigated. This may be important in establishing pre-event conditions prior to initiating the transient analyses.

- Magnitude of loop transient (i.e., 50 cent insertion). For the pipe break, was the worst experiment package assumed (i.e., the test that would yield the largest reactivity insertion)? As we understand the situation, the 50 cent insertion transient had been used in an earlier benchmark, and was only used for comparison with earlier results. It was not intended to represent a maximum insertion. If indeed the purpose of the analysis is to provide methods, this is appropriate. If, however, the purpose is to define reactor safety, a stronger case on the bounding nature of the event chosen would improve the defensibility of the analysis.

- Validation experiments and calculations. We understand that selected validation experiments and calculations were performed during FY91 with further assessments planned. The list of available experimental data was impressive. Although we did not see these results, such experiments may allay some of the concerns noted in this report. 
- In the methods document (Judd 1991), it is indicated that the basis of the reactivity coefficients and the validation was to be documented separately. Again, we did not see this basis, and it could allay some of the concerns noted in this report.

- Reactivity input for loop voiding accident. The decrease in reactivity after 0.4 seconds is puzzling. It is implied that the regulation rod plays a role. If this is an ATWS, are you allowed to take credit for any control rod motion? And if so, can you defend rod motion in 0.1 seconds? A clearer explanation is perhaps warranted.

- Control system model. How realistic is the control system approximation, since it is important to determine the temperature feedback? How did the control do in the benchmark, or could that aspect of the model be tested in comparison to the benchmark? A careful review of the sensitivity of the results to the control system model and its assumptions along with a more comprehensive explanation of the control system is appropriate.

- Neutronics simulation of test loops. EG\&G personnel stated that they often do not know the actual loading of test loops, only the "hafnium equivalent". This may be (marginally) adequate for keff and burnup calculations, but it is certainly insufficient for coolant void calculations. The spectral variation for a given test loading, for example, would be completely lost in a "hafnium equivalent" method. Although other organizations may have performed some sort of voiding estimates, it does not appear that EG\&G Idaho has sufficient information for comprehensive input to RELAP. It is recommended that some attempt be made to close this information gap.

- Sensitivity testing. After our initial reading of the sensitivity testing on the secondary inlet temperature, we questioned the one sided nature of the test. That is, the sensitivity test indicated that increasing the secondary inlet temperature lead to a more benign event. This appeared to leave the potential for decreasing the temperature to cause a more severe event. On further study, we understood the raise was during the event, reflecting a conservative impact on the secondary of the higher heat load. Since the power does increase during this event, a reduction in the secondary temperature during the event is not credible. Therefore, the one sided sensitivity test is appropriate. It may be of value to enhance the description to help the reader to avoid the logic trap which captured us initially. 


\subsection{REFERENCES}

1. Polkinghorne, S.T. 1990. Anticipated Transient without Scram Analyses for the ATR Level 2 PRA, Internal Technical Report, PG-T-91-006, EG\&G Idaho.

2. Judd, J.L. and Terry, W.K. 1991. RELAP5 Kinetics Model Development for the Advanced Test Reactor, Internal Technical Report, NRRT-N-91-009, EG\&G Idaho. 


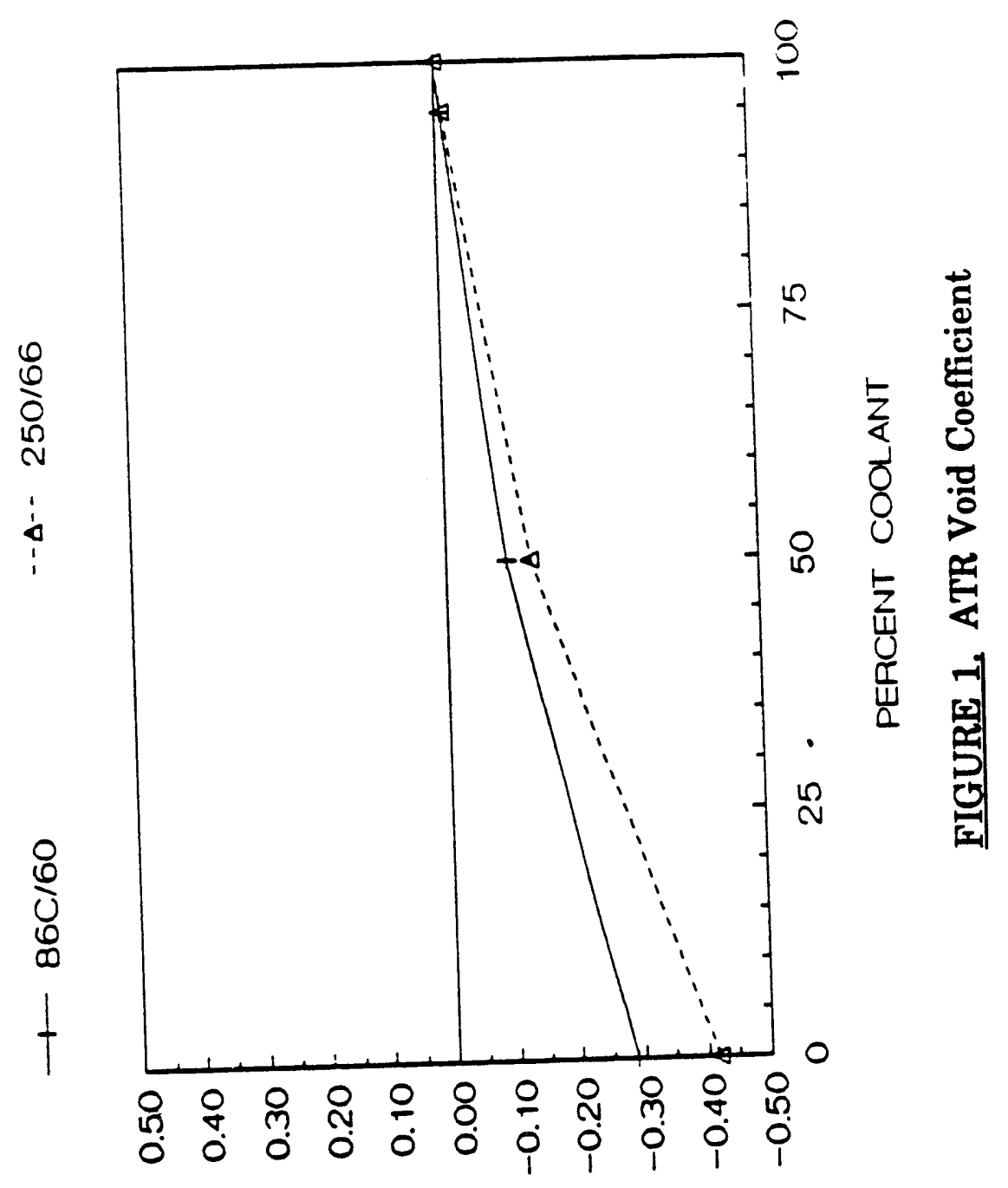

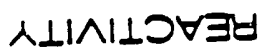




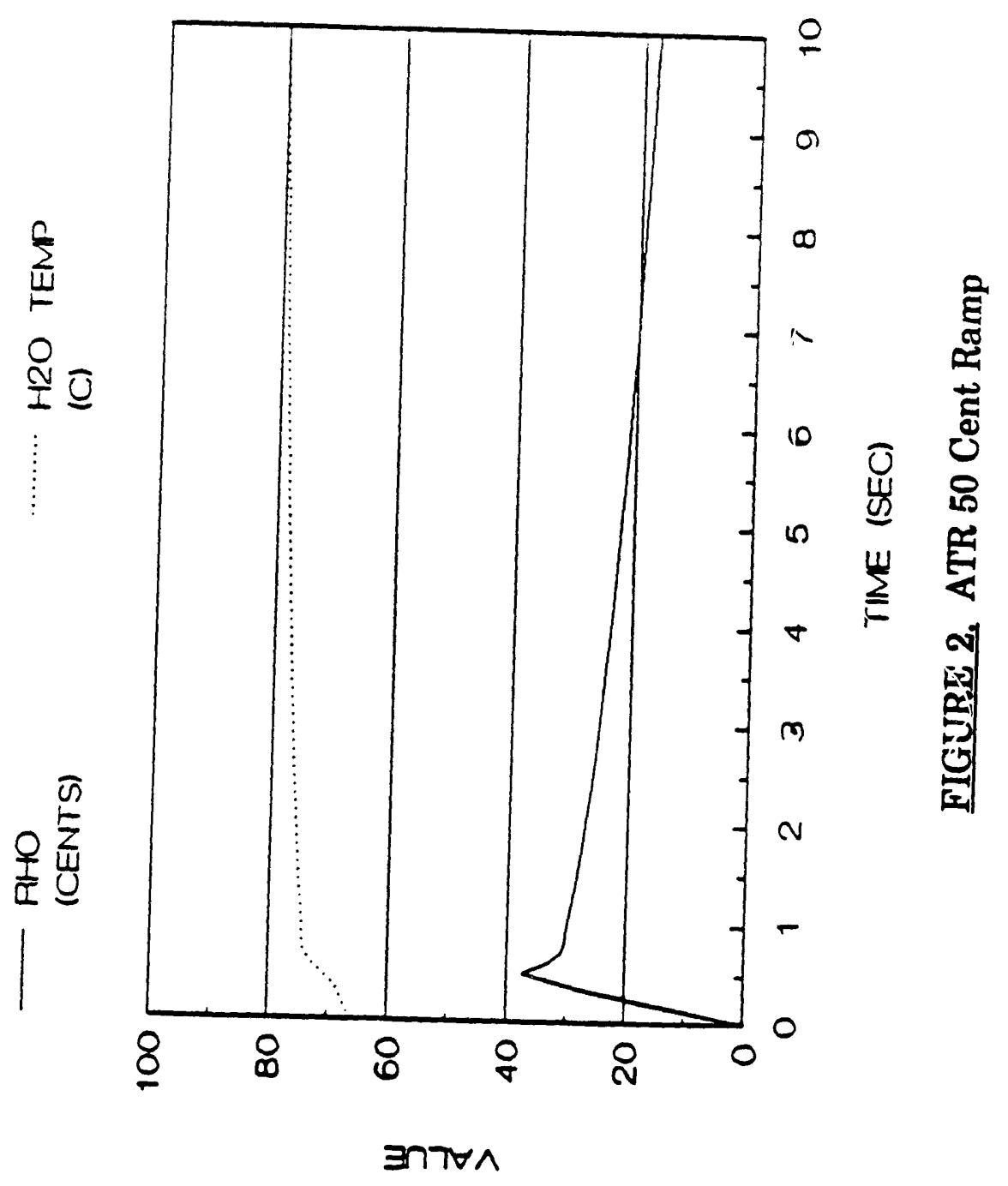




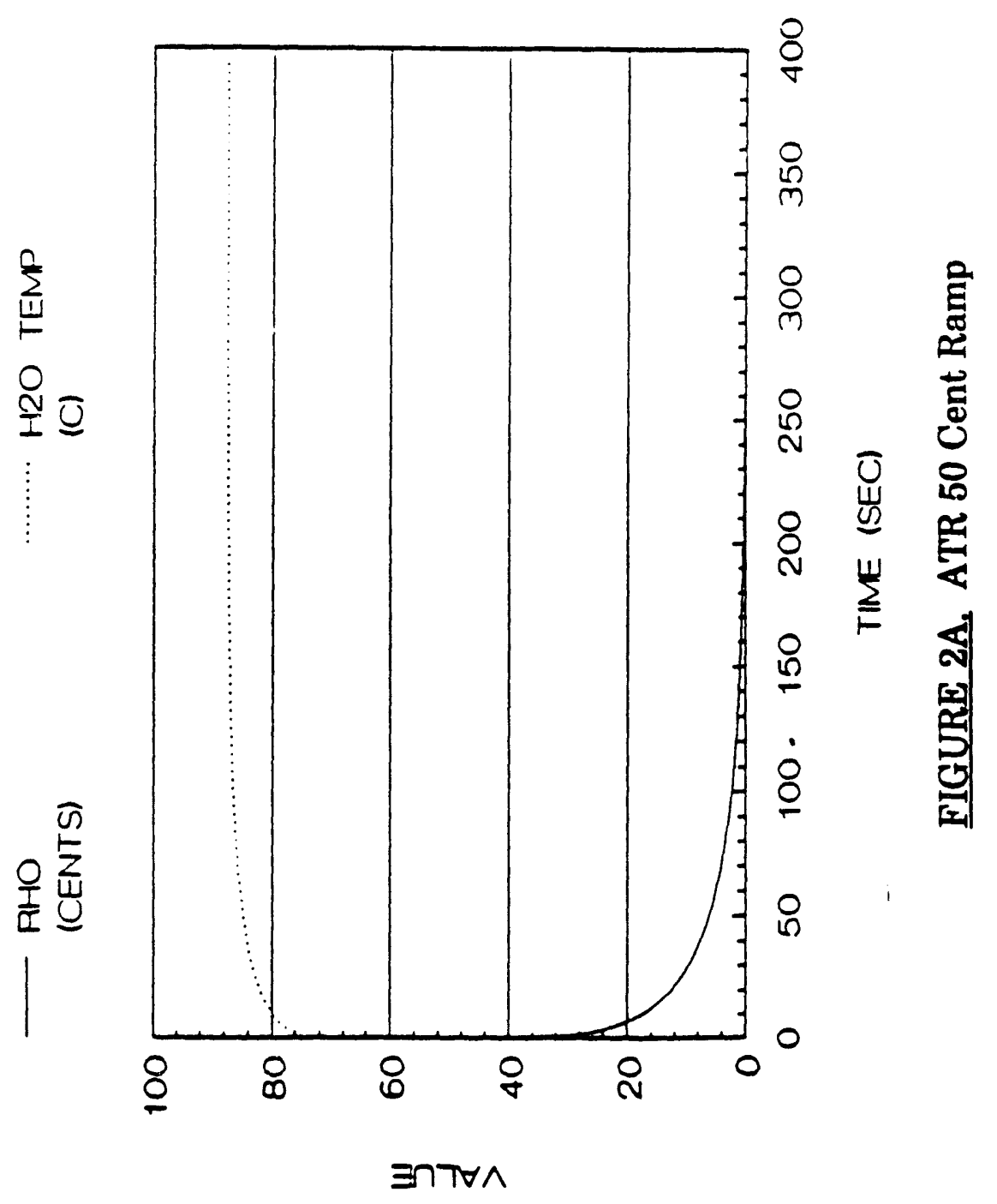


สI

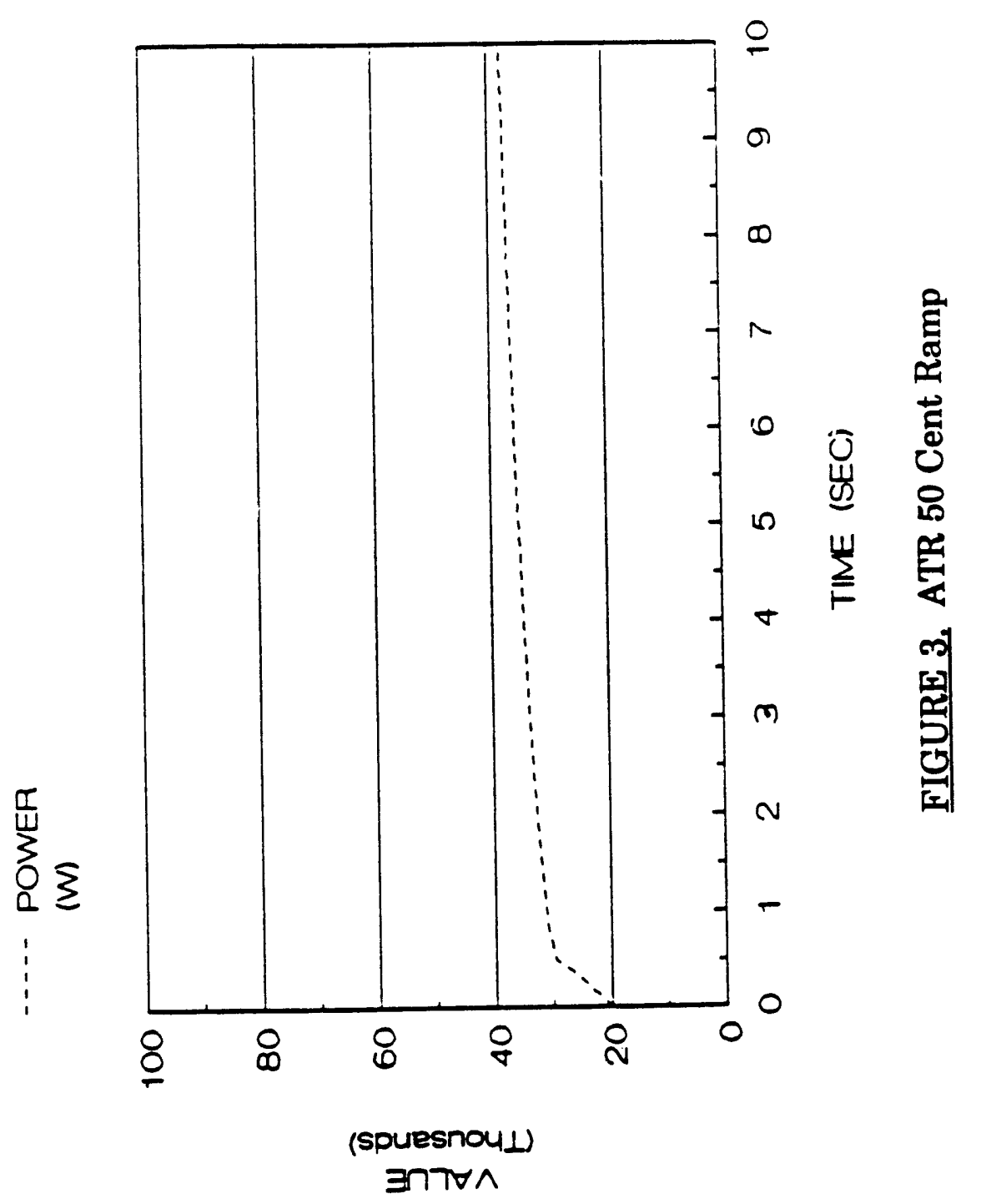




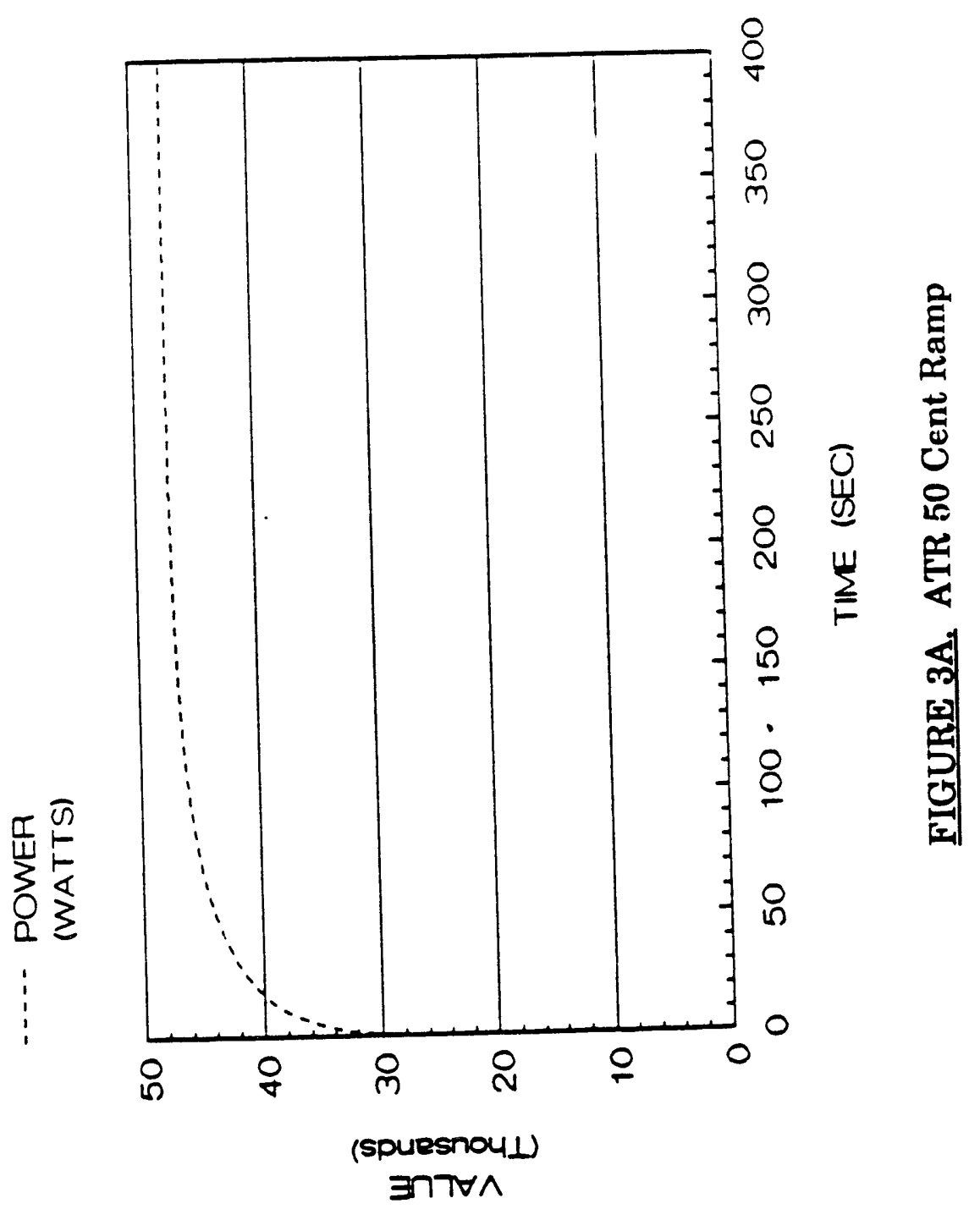




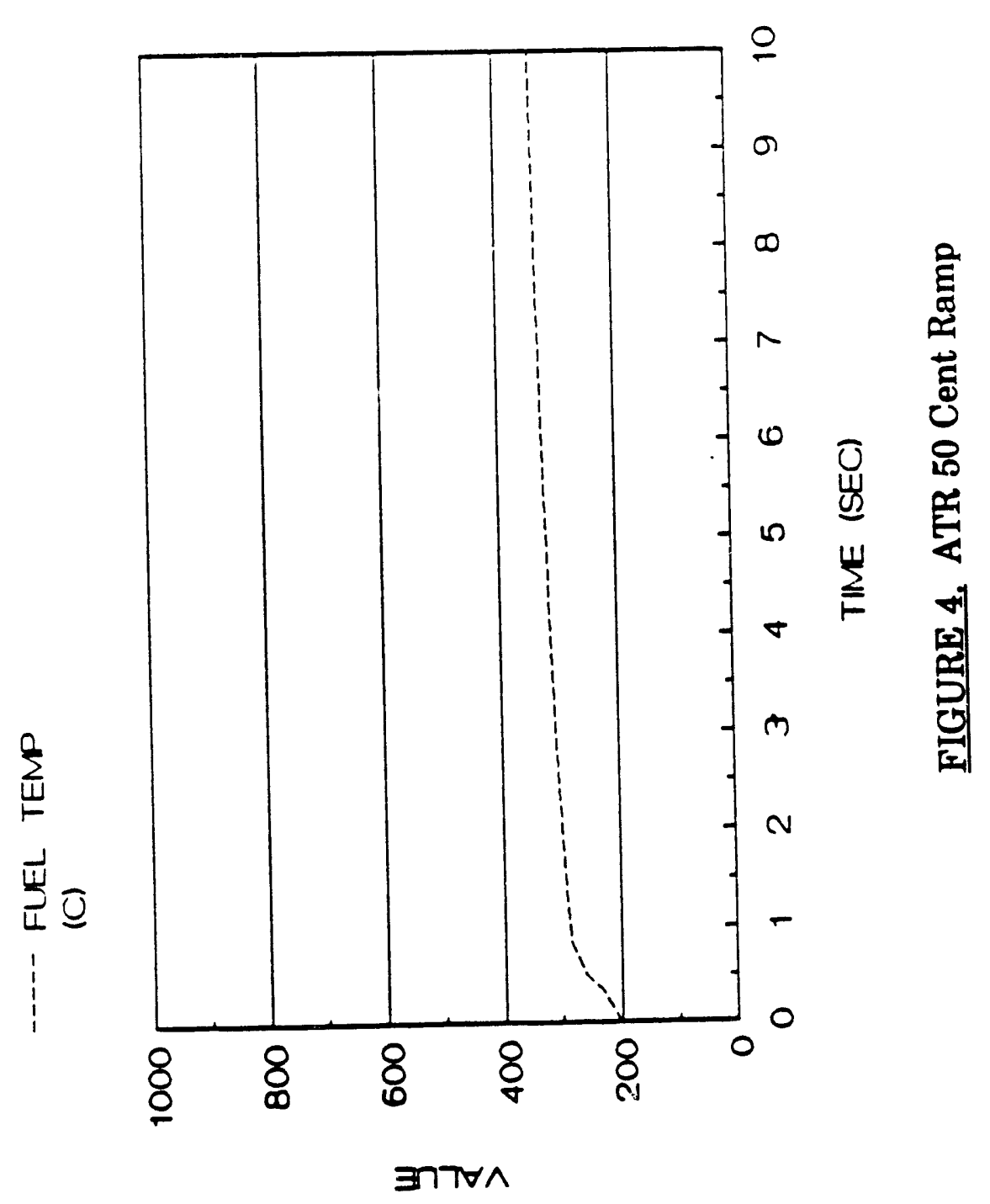




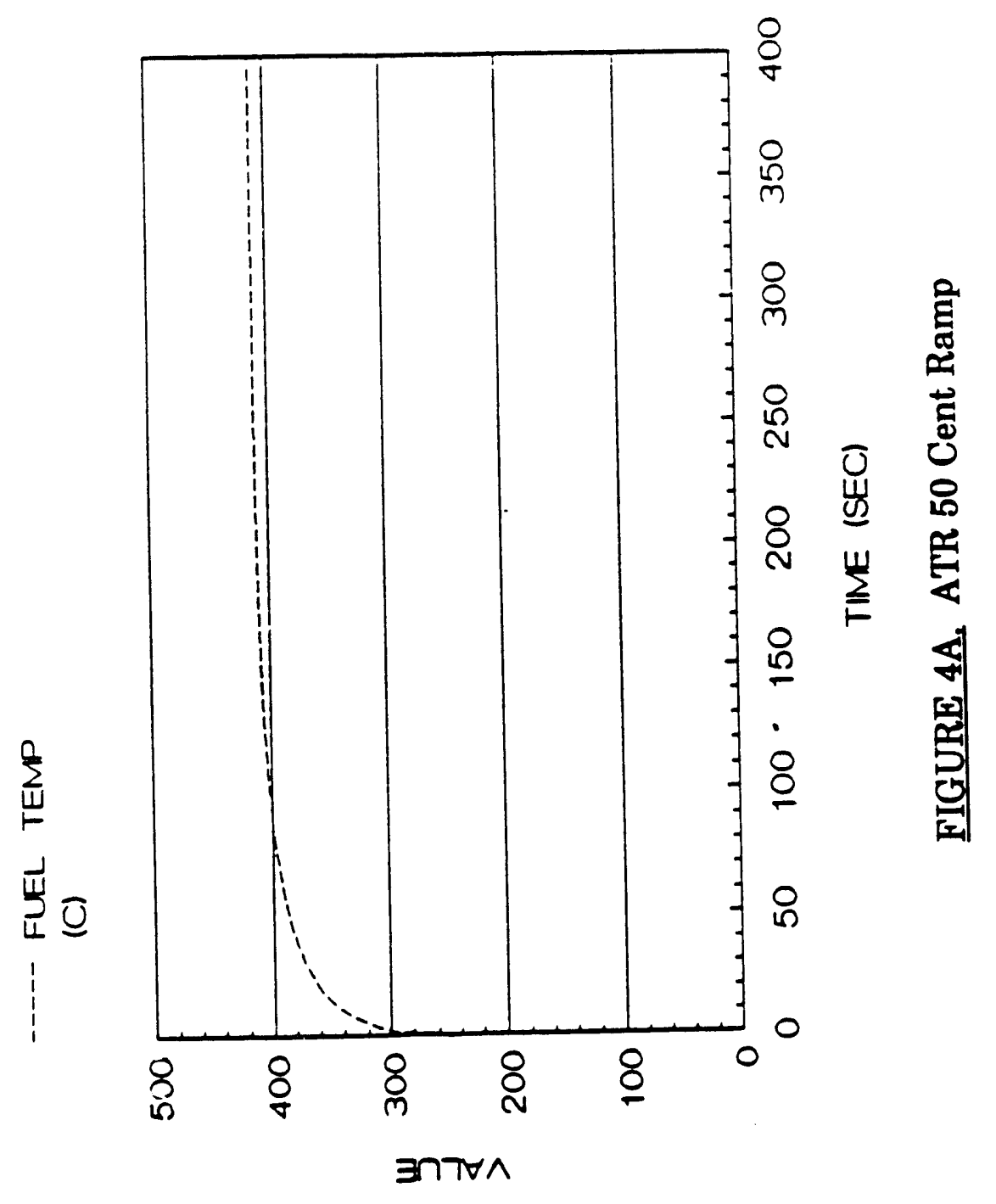




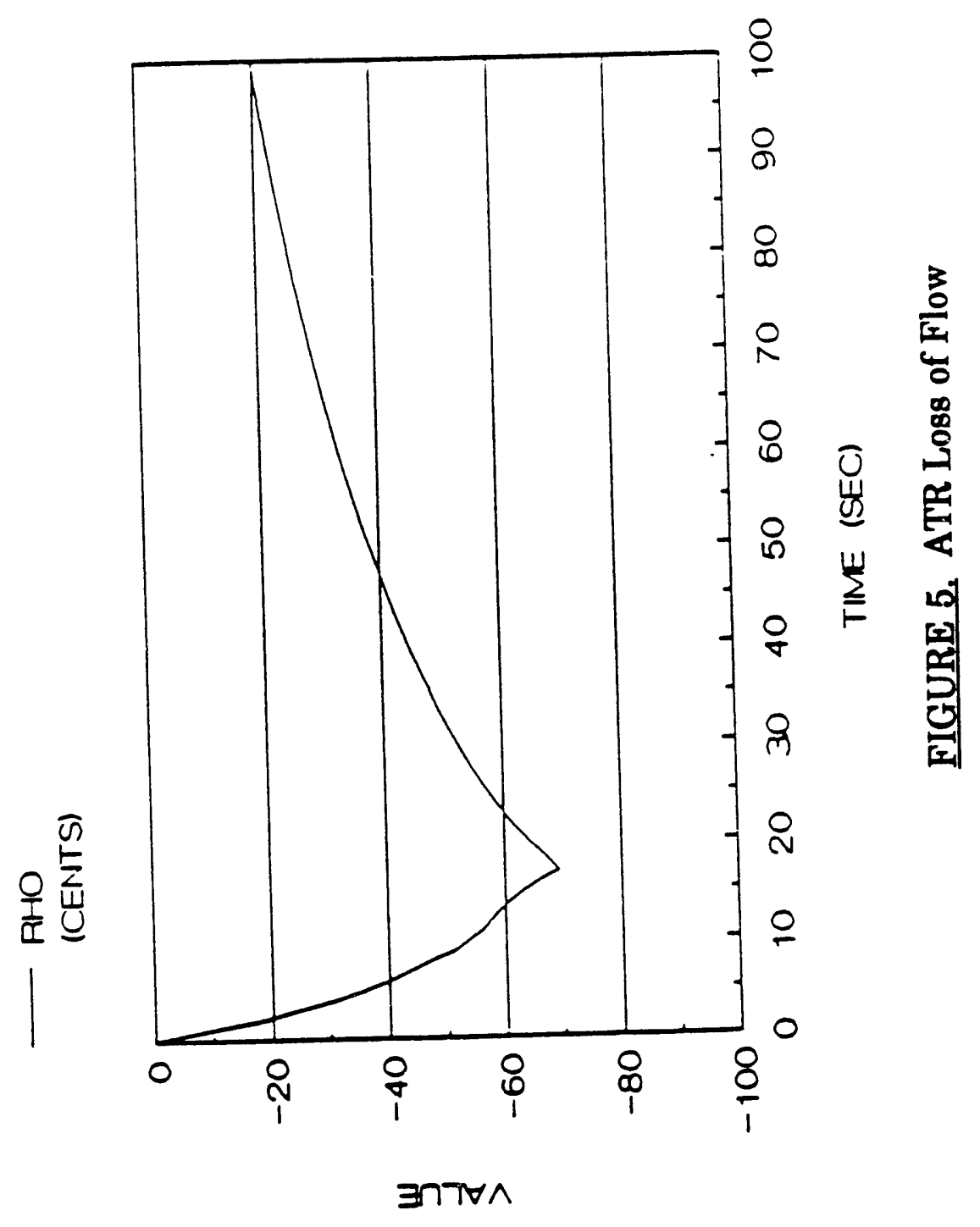




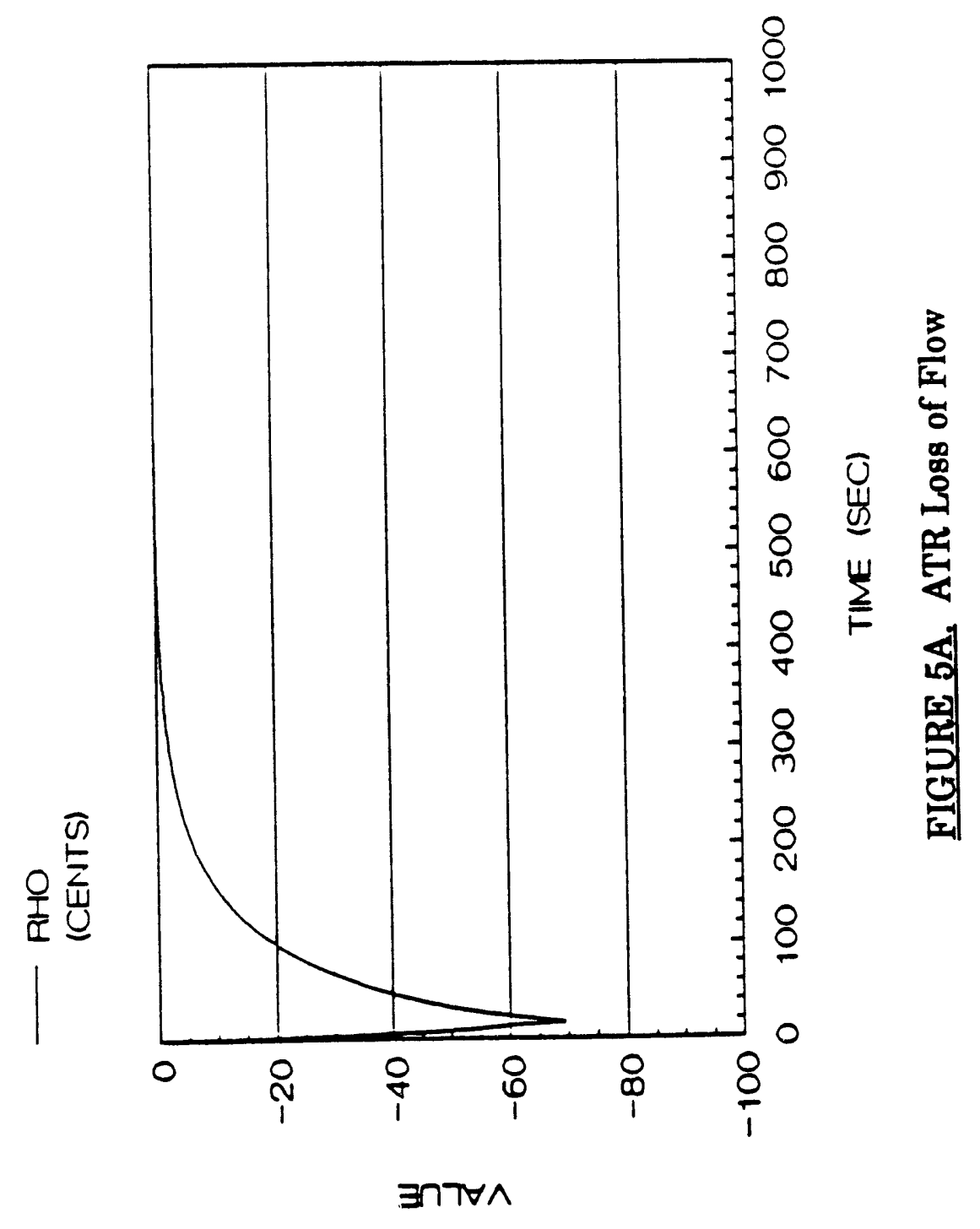




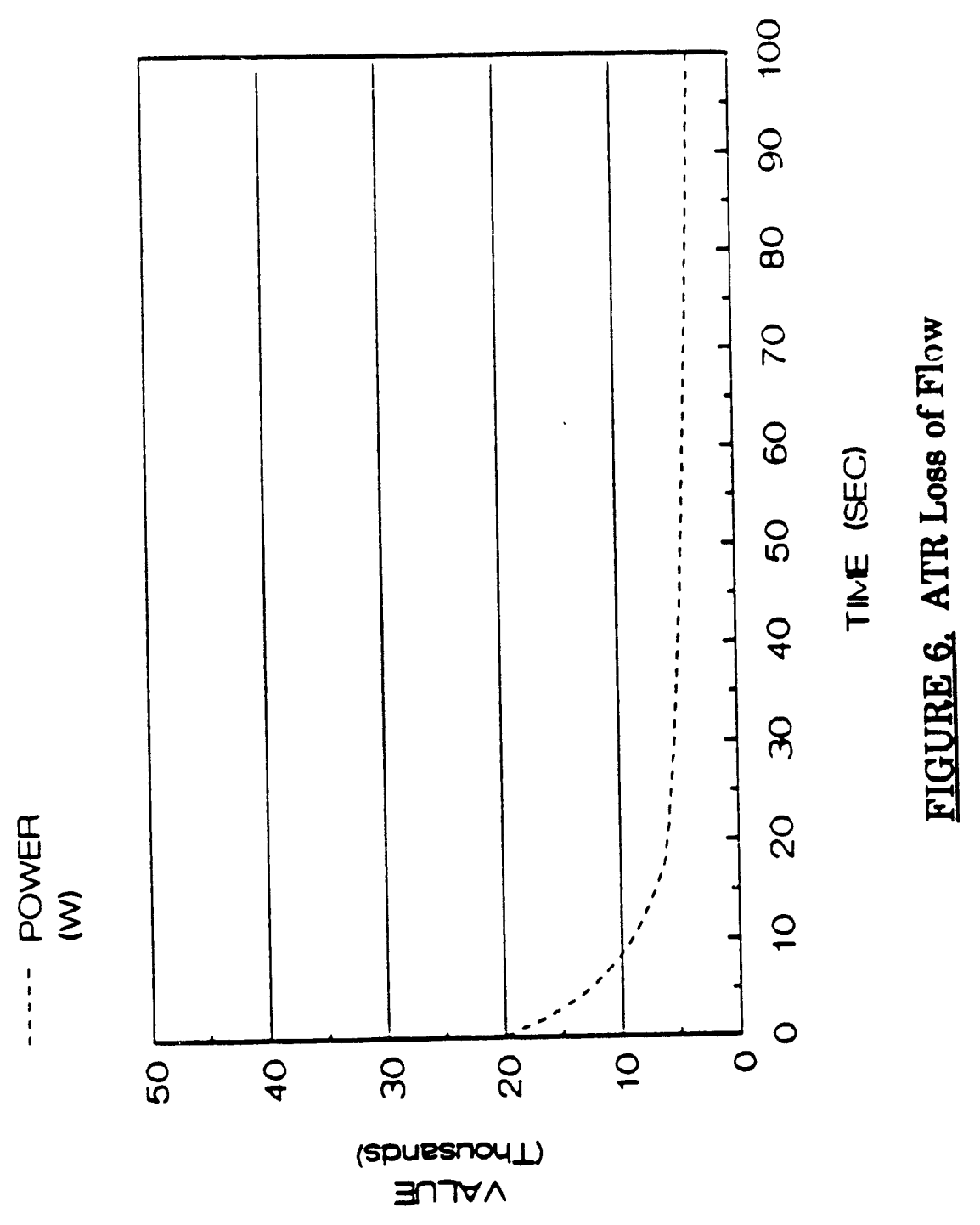




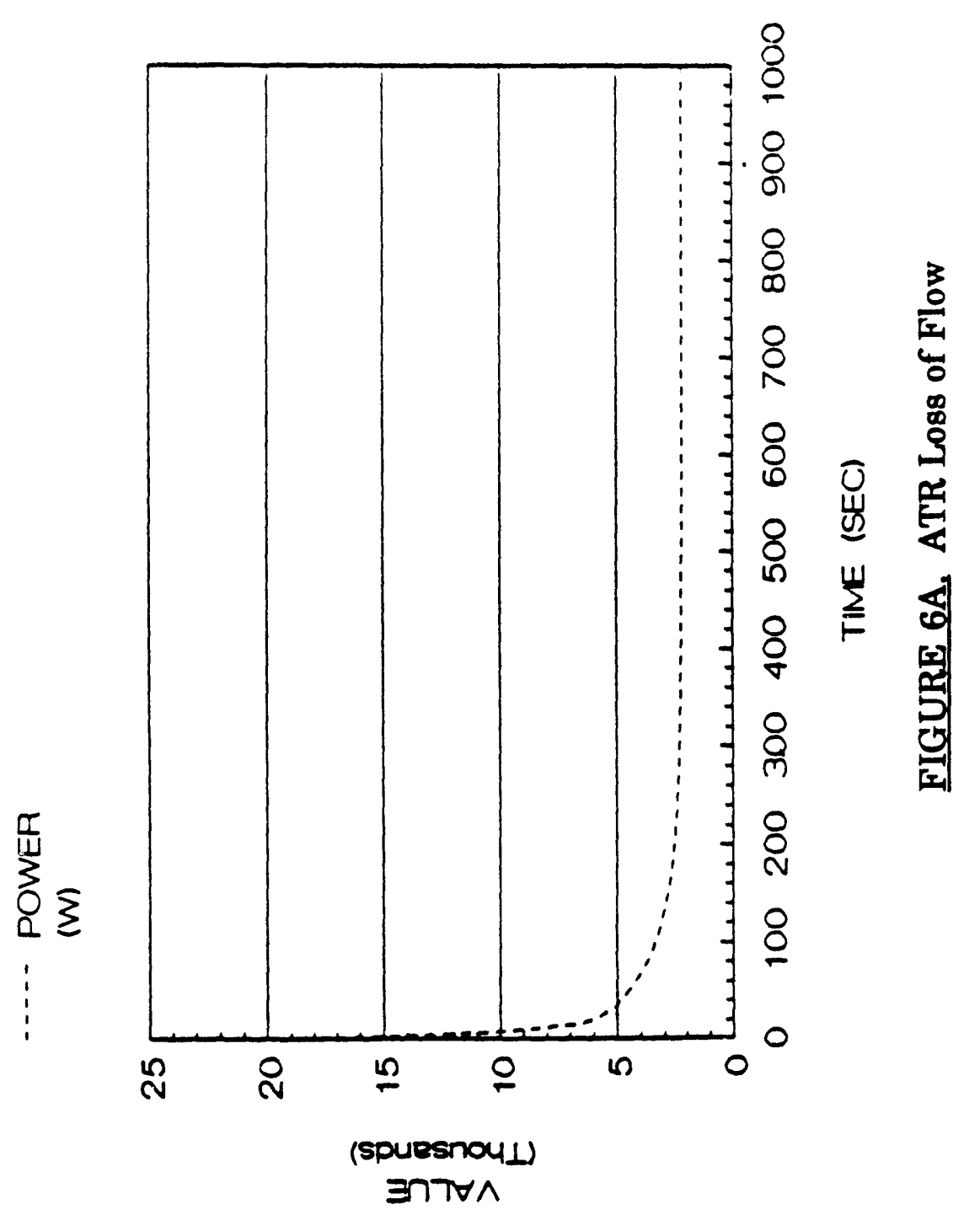




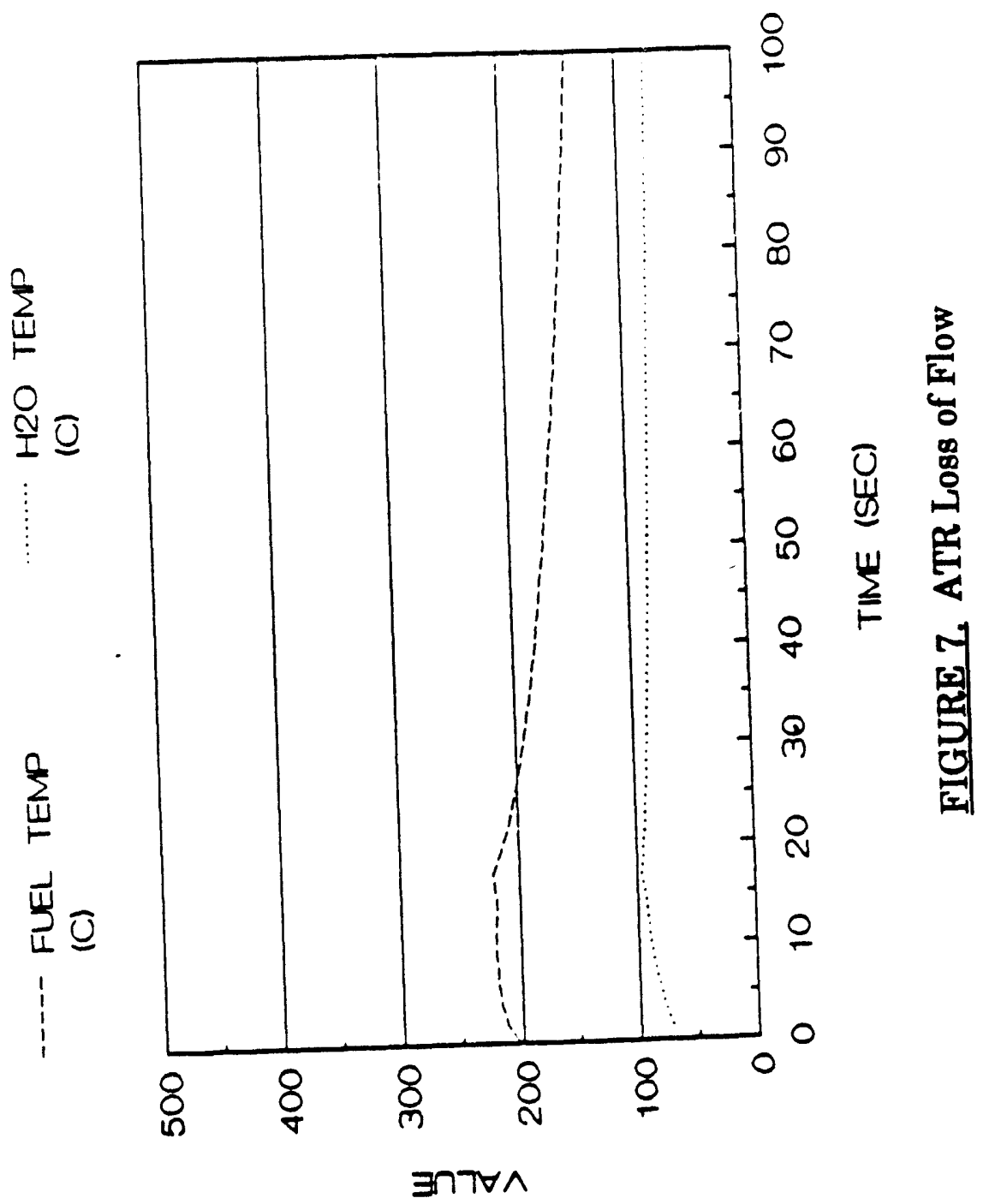




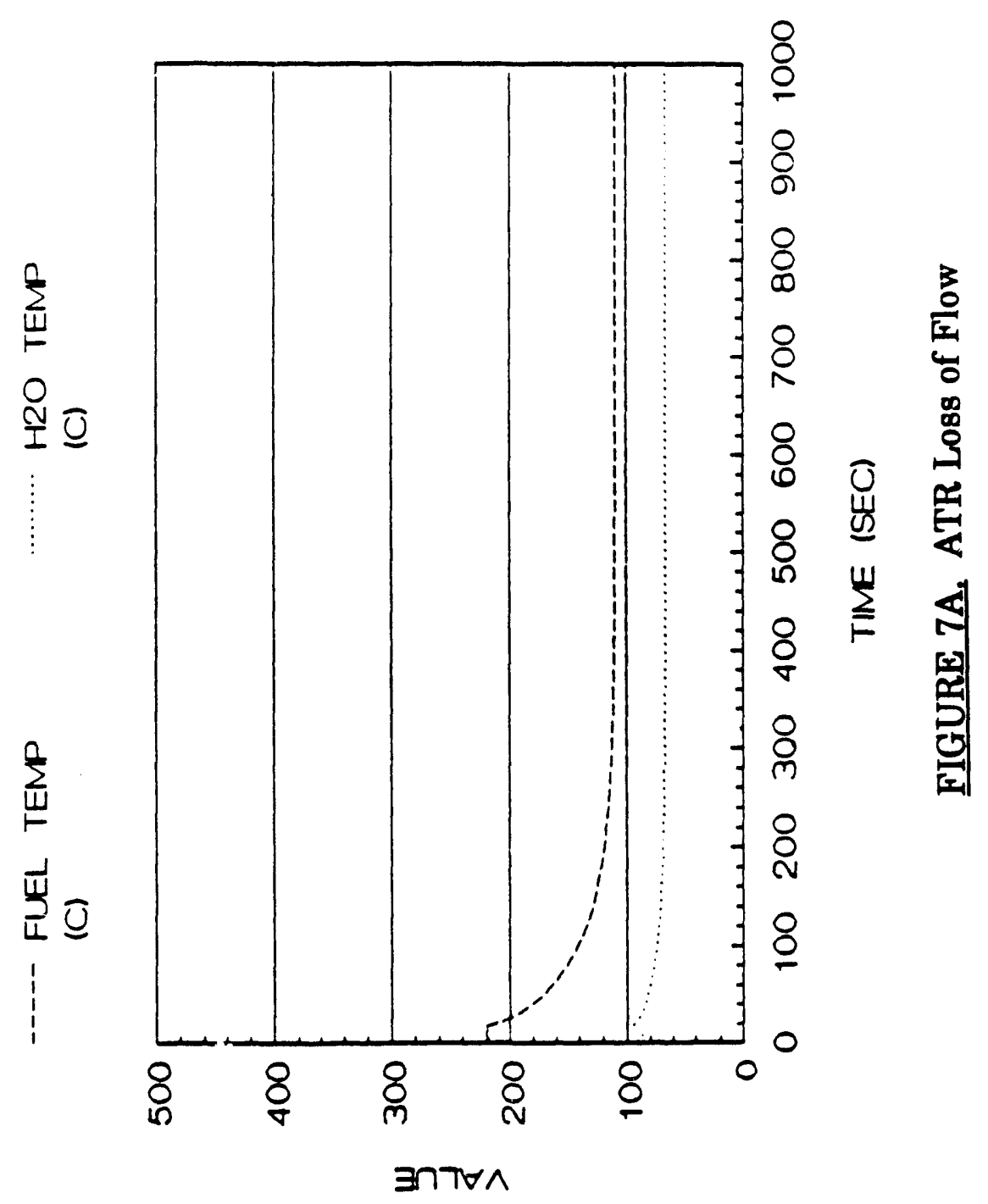


PNL-7825

UC-610

\section{DISTRIBUTION}

No. of

- Copies

\section{OFESITE}

12 DOE/Office of Scientific and Technical Information

S. A. Atkison

Idaho National Engineering Laboratory EG\&G Idaho, Inc.

P. O. Box 1625

Mail Stop 7121

Idaho Falls, ID 83415

J. L. Durney

Idaho National Engineering Laboratory EG\&G Idaho, Inc.

P. O. Eox 1625

Mail Stop 7121

Idaho Falls, ID 83415

J. L. Judd

Idaho National Engineering Laboratory EG\&G Idaho, Inc.

P. O. Box 1625

Mail Stop 1575

Idaho Falls, ID 83415

S. R. Wagoner (5)

Idaho National Engineering Laboratory EG\&G Idaho, Inc.

P. O. Box 1625

Mail Stop 7121

Idaho Falls, ID 83415

R. P. Wadkins

Idaho National Engineering Laboratory EG\&G Idaho, Inc.

P. O. Box 1625

Mail Stop 1575

Idaho Falls, ID 83415
No. of

Copies

ONSITE

10 Pacific Northwest Laboratory

L. R. Dodd

S. W. Heaberlin (2)

W. W. Little

Publishing Coordination

Technical Report Files (5) 

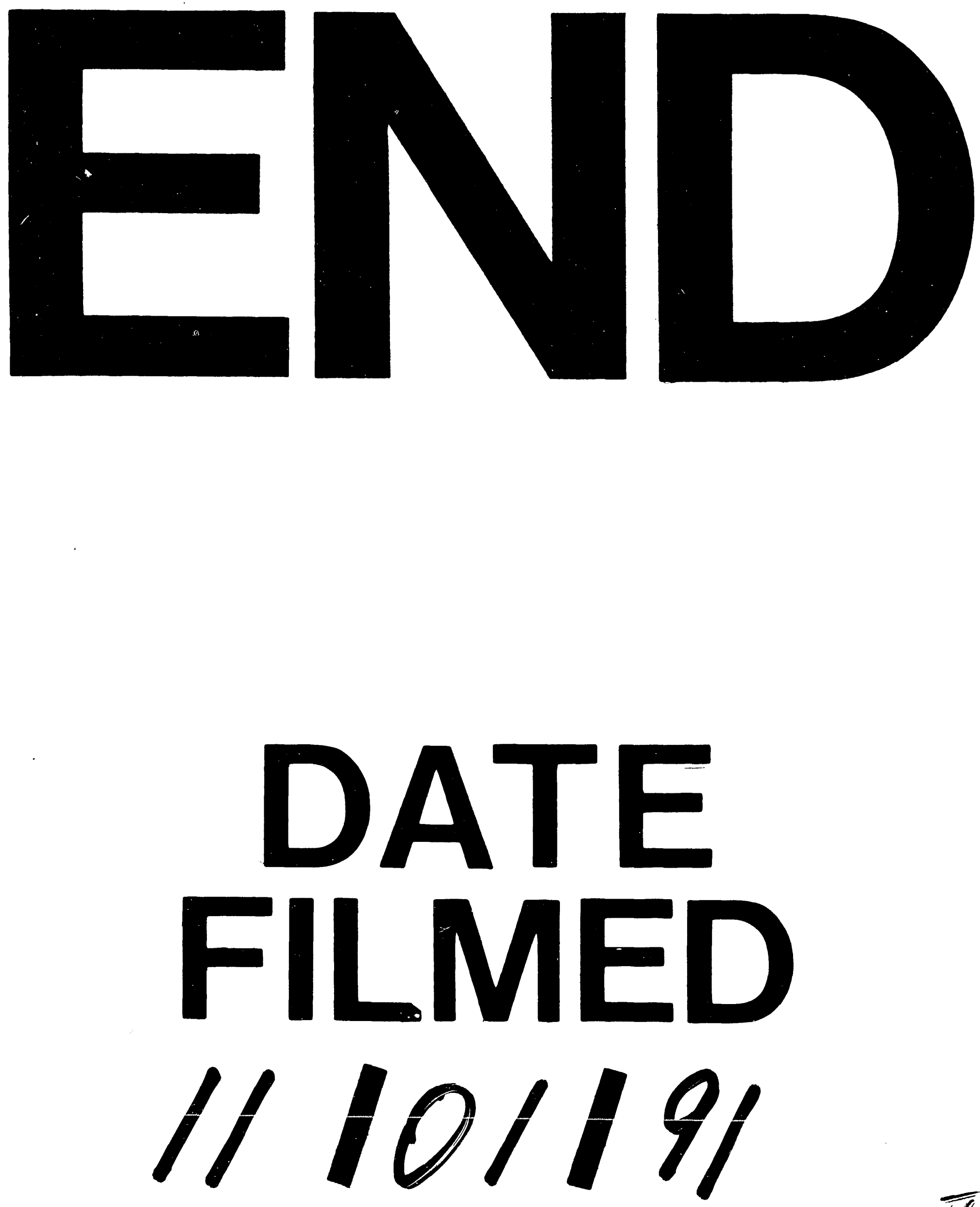
